\title{
Suggestions about medications of proven effectiveness without commercial interest for the pharmaceutical industry
}

Manuel De la Llata, José Hálabe, Ricardo Plancarte, Oscar Arrieta, Rubén Burgos, Carlos Campillo, Miguel Ángel Celis, Judith Domínguez, Sergio Islas, Luis Jasso, Alberto Lifshitz, Mucio Moreno, Alejandro Reyes, Guillermo Ruiz-Argüelles, Antonio Soda, Emma Verástegui and Julio Sotelo Academia Nacional de Medicina, Comité de Ética y Transparencia en la Relación Médico-Industria (Cetremi), Ciudad de México, Mexico

\begin{abstract}
Several drugs with adequate efficacy have been withdrawn from the market for financial reasons, either due to their reduced price (the patent has expired) or because they have been substituted with new drugs (with patents in force); many others have not been developed because the diseases they are directed against are not economically promising owing to the type of population that suffers from them (economically marginalized or numerically non-significant strata). Guidelines and incentives for the pharmaceutical and biotechnological industry should be established.
\end{abstract}

KEY WORDS: Drug production. Pharmaceutical industry. Drug research and development.

The process that goes from the discovery of a new molecule to its commercialization is long, with a mean of 10 years, it is expensive, on average several million dollars, and its potential efficiency is uncertain: out of 10 molecules tested, only one manages to have significant therapeutic effect. Developing or continuing the production of a drug aimed at treating diseases that do not allow, in general, to recover the capital invested for their research and generating substantial profit is unattractive from the business perspective.

Medications without major interest for the pharmaceutical industry can be grouped in three types according to their characteristics:

- Products withdrawn from the market for economic or therapeutic reasons (with the arrival of new drugs and more profitable molecules).

- Products that have not been developed.

- "Orphan" products, aimed at treating rare diseases.

\section{Products withdrawn from the market for economic reasons}

Various active and medically convenient drugs, whose effectiveness has historically been confirmed, have been withdrawn from the market for two fundamental reasons: their price in the market is reduced, since the patent has expired and they do not have acceptable financial profit margins for manufacturers, or have been replaced by new drugs with patents in force, which represent a more attractive economic possibility, although therapeutic effectiveness is of marginal superiority, a situation that has been observed in drugs of practically all medical specialties. For example, thalidomide was widely used as a hypnotic and antiemetic drug many years ago, but it was withdrawn from the market when its high teratogenic risk was discovered; subsequently, its specific analgesic and immunomodulatory properties were identified in diseases such as leprosy, lupus erythematosus
Gac Med Mex. 2018;154:456-457

Contents available at PubMed www.gacetamedicademexico.com 
and myeloma multiple, for which there is no satisfactory alternative treatment available. This drug had to be accessible for new indications and at a modest price, without neglecting the necessary precautions for its prescription.

\section{Products that have not been developed}

Such situations derive from research processes that do not encourage for certain products to be formulated or patented because, even when a large number of people are affected (for example, infectious and parasitic diseases of economically poor countries), they are financially unattractive or because the diseases against which they are directed are not economically promising in market studies.

\section{"Orphan" products, aimed at treating rare diseases}

These products are developed to treat patients suffering from serious conditions that do not have a satisfactory treatment; however, these diseases affect a very small proportion of the population, often since birth or childhood. The number of rare diseases that affect less than 5 people per 10000 population, with the number of those that currently do not have treatment available being estimated to range between 4000 and 5000. This group of ailments are far from numerically representing the epidemiological concern described in groups I and II for current medicine.

\section{Suggestions of the Committee of Ethics and Transparency in the Physician-Industry Relationship}

To stimulate research and development of this broad group of medications, in support of the social practice of medicine, the authorities should establish guidelines and incentives for the pharmaceutical and biotechnology industry.

Both initial general subgroups are of the utmost importance: they refer to therapeutically useful drugs, but that were withdrawn from the market for strictly economic reasons of the manufacturers. Here, it is advisable highlighting that drugs withdrawn for financial circumstances have left a worrying therapeutic void, since a large number of them have validity and precise and valuable medical indications, as for example, in cardiology, quinidine, in dermatology, diamino-diphenyl-sulphone, in neurology, acetazolamide, in psychiatry, several tricyclic antidepressants, etc.

Favorable actions adopted by health authorities to address this issue have been almost exclusively aimed at orphan drugs, which only represent one of the 3 indicated subgroups, that is, attention to the problem has been limited only to the products aimed at treating rare diseases.

The Ethics and Transparency Committee in the Physician-Industry Relationship (Cetremi - Comité de Ética y Transparencia en la Relación Médico-Industria) considers it to be indispensable for the chambers that represent the pharmaceutical industry to establish the obligation and necessary incentives for pharmaceutical production laboratories to maintain or resume the production of products that have been withdrawn or are soon to be withdrawn from the market for not being economically profitable or productive.

In other countries, the incentives the law offers to pharmaceutical companies in order to encourage them to investigate and produce medications of little financial interest are:

- "Market exclusivity" for several years.

- Incentives to clinical research.

- Subsidies for the development of clinical trials.

- Favorable tax cut agreements.

We suggest to the Federal Commission for Protection against Health Risk (Cofepris - Comisión Federal para la Protección contra Riesgos Sanitarios) and to the corresponding government authorities, to assess the adoption or promotion of similar practices in Mexico, since there is a large amount of medications that have been withdrawn from the national market for not being economically attractive to their manufacturers in the pharmaceutical industry and, in consequence, the field of curative action and medical treatment options has considerably decreased. But yet more importantly, access to effective and affordable treatments has been restricted, with this being a worrying circumstance, especially in patients with economic limitations, which in Mexico represent a large percentage of the population. 